\title{
Fatigue and sleep disorders in multiple sclerosis: is obstructive sleep apnea a link?
}

\author{
Friedemann Paul • Christian Veauthier
}

Received: 22 December 2011 /Revised: 22 December 2011 / Accepted: 29 December 2011 /Published online: 18 January 2012

(C) Springer-Verlag 2012

In this small pilot study, published in the current issue of Sleep and Breathing, Dias and colleagues [1] try to identify multiple sclerosis (MS) patients who are at risk for obstructive sleep apnea (OSA) by applying the STOP-BANG questionnaire which has been validated as a screening tool for OSA in various populations, but not yet in MS patients [2]. Interestingly, almost half of the cohort exhibited STOPBANG scores indicative of a high OSA risk, which was approximately threefold higher in men than in women. In men, a significant correlation between STOP-BANG scores and measures of daytime sleepiness (Epworth Sleepiness Scale) and fatigue (Fatigue Severity Scale) was reported. Although the study has some obvious methodological limitations discussed by the authors, such as a lack of a subsequent polysomnography (PSG) to confirm the presence of OSA in patients at high risk according to the STOP-BANG questionnaire, the attempt to shed light on the elusive influence of nocturnal sleep abnormalities on daytime sleepiness

\footnotetext{
F. Paul $(\square)$

NeuroCure Clinical Research Center and Experimental and Clinical Research Center, Charité University Medicine Berlin, Charitéplatz 1,

10117 Berlin, Germany

e-mail: friedemann.paul@charite.de

F. Paul

Max Delbrueck Center for Molecular Medicine,

Berlin, Germany

F. Paul

Clinical and Experimental Multiple Sclerosis Research Center, Charité University Medicine Berlin,

Berlin, Germany

C. Veauthier

Department of Neurology, Hanse-Klinikum Stralsund, Stralsund, Germany
}

and fatigue in MS is laudable. Fatigue is defined as "a subjective lack of physical and/or mental energy that is perceived by the individual or caregiver to interfere with usual and desired activities" [3]. Fatigue is the most frequent MS symptom, reported by up to $97 \%$ of patients [4-6], two thirds of whom consider it as their most disabling symptom [7]. Fatigue does not only exert a substantial negative impact on quality of life, but is also a major cause of unemployment in MS [8]. Fatigue has been related to neuroimaging findings [9], neuroendocrine dysregulation [10], XMRV virus infections [11], depression and cognitive dysfunction $[12,13]$. However, despite its high prevalence, our knowledge on pathophysiology and treatment of MS-related fatigue is insufficient. Unfortunately, many neurologists exhibit a therapeutic nihilism towards this debilitating symptom in regarding fatigue as some immanent and intractable feature of the condition with which the patient "has to learn to live". Only in recent years, a possible association of daytime fatigue with sleep disorders has become into focus; however, only very few studies have attempted to investigate the relationship between sleep disorders in general and MS-related fatigue by PSG or accelerometry and not only by questionnaires on sleep quality [14-17]. In sum, it is undoubtful that sleep disorders can contribute to daytime fatigue in MS. In a recently published study [18], the authors proposed a screening instrument for sleep disorders because owing to limited resources not every MS patient complaining of fatigue can be admitted to a sleep laboratory. Beyond that, it makes sense to develop a screening instrument especially for OSA in the context of MS-related fatigue to identify patients at high risk. Further polysomnographic investigations have to validate this specific STOP-BANG questionnaire in the context of MS-related fatigue. Secondly, prospective studies have to evaluate whether a consequent treatment of the respective sleep disorder will beneficially influence fatigue in MS. If this can be demonstrated, a new therapeutic horizon 
opens up for MS patients with fatigue as many sleep disorders, among them OSA, can be satisfactorily treated.

Although the exact prevalence of OSA in MS remains to be elucidated, the work by Dias and colleagues [1] emphasizes that every physician treating MS patients should be aware of the burden fatigue may pose on the affected patient and also of underlying sleep disorders such as OSA.

Acknowledgements FP is supported by the German Research Foundation (DFG Exc 257).

\section{References}

1. Dias RA, Hardin KA, Rose H, Agius MA, Apperson ML, Brass SD (2012) Sleepiness, fatigue, and risk of obstructive sleep apnea using the STOP-BANG Questionnaire in multiple sclerosis: a pilot study. Sleep and Breathing (in press)

2. Abrishami A, Khajehdehi A, Chung F (2010) A systematic review of screening questionnaires for obstructive sleep apnea. Can J Anaesth 57:423-438

3. Multiple Sclerosis Council for Clinical Practice Guidelines (1998) Fatigue and multiple sclerosis: evidence-based management strategies for fatigue in multiple sclerosis. Paralyzed Veterans of America, Washington, DC

4. Lerdal A, Celius EG, Mourn T (2003) Fatigue and its association with sociodemographic factors among multiple sclerosis patients. Mult Scler 9:509-514

5. Bakshi R (2003) Fatigue associated with multiple sclerosis: diagnosis, impact and management. Mult Scler 9:219-227

6. Krupp L (2006) Fatigue is intrinsic to multiple sclerosis (MS) and is the most commonly reported symptom of the disease. Mult Scler 12:367-368

7. Krupp LB, LaRocca NG, Muir-Nash J, Steinberg AD (1989) The fatigue severity scale. Application to patients with multiple sclerosis and systemic lupus erythematosus. Arch Neurol 46:1121-1123
8. Smith MM, Arnett PA (2005) Factors related to employment status changes in individuals with multiple sclerosis. Mult Scler 11:602609

9. Pellicano C, Gallo A, Li X, Ikonomidou VN, Evangelou IE, Ohayon JM, Stern SK, Ehrmantraut M, Cantor F, McFarland HF, Bagnato F (2010) Relationship of cortical atrophy to fatigue in patients with multiple sclerosis. Arch Neurol 67:447-453

10. Gottschalk M, Kümpfel T, Flachenecker P, Uhr M, Trenkwalder C, Holsboer F, Weber F (2005) Fatigue and regulation of the hypothalamo-pituitary-adrenal axis in multiple sclerosis. Arch Neurol 62:277-280

11. Hohn O, Strohschein K, Brandt AU, Seeher S, Klein S, Kurth R, Paul F, Meisel C, Scheibenbogen C, Bannert N (2010) No evidence for XMRV in German CFS and MS patients with fatigue despite the ability of the virus to infect human blood cells in vitro. PLoS ONE 5 (12):e15632

12. Krupp LB, Elkins LE (2000) Fatigue and declines in cognitive functioning in multiple sclerosis. Neurology 55:934-939

13. Flachenecker P, Kumpfel T, Kallmann B, Gottschalk M, Grauer O, Rieckmann P, Trenkwalder C, Toyka KV (2002) Fatigue in multiple sclerosis: a comparison of different rating scales and correlation to clinical parameters. Mult Scler 8:523-526

14. Ferini-Strambi L, Filippi M, Martinelli V, Oldani A, Rovaris M, Zucconi M, Comi G, Smirne S (1994) Nocturnal sleep study in multiple sclerosis: correlation with clinical and brain magnetic resonance imaging findings. J Neurol Sci 125:194-197

15. Kaynak H, Altintas A, Kaynak D, Uyanik O, Saip S, Agaoglu J, Onder G, Siva A (2006) Fatigue and sleep disturbance in multiple sclerosis. Eur J Neurol 13:1333-1339

16. Attarian HP, Brown KM, Duntley SP, Carter JD, Cross AH (2004) The relationship of sleep disturbances and fatigue in multiple sclerosis. Arch Neurol 61:525-528

17. Veauthier C, Radbruch H, Gaede G, Pfueller CF, Dörr J, BellmannStrobl J, Wernecke KD, Zipp F, Paul F, Sieb JP (2011) Fatigue in multiple sclerosis is closely related to sleep disorders: a polysomnographic cross-sectional study. Mult Scler 17:613-622

18. Veauthier C, Paul F (2012) Fatigue in multiple sclerosis: which patient should be referred to a sleep specialist? Mult Scler. doi:10.1177/1352458511411229 